\title{
Atomic Engineering Bifunctional Niobium (V)-based Heterostructure Nanosheet for High Efficiency Lean- Electrolyte Lithium-Sulfur Full Batteries
}

\section{Haodong Shi}

Dalian Institute of Chemical Physics, Chinese Academy of Sciences

Jieqiong Qin

Dalian Institute of Chemical Physics

Pengfei Lu

Dalian Institute of Chemical Physics

Cong Dong

Dalian Institute of Chemical Physics

\section{Pratteek Das}

Dalian Institute of Chemical Physics

\section{Jiemin Wang}

Dalian Institute of Chemical Physics, Chinese Academy of Sciences

\section{Liangzhu Zhang}

Dalian Institute of Chemical Physics, Chinese Academy of Sciences

\section{Zhong-Shuai Wu ( $\nabla$ wuzs@dicp.ac.cn )}

Dalian Institute of Chemical Physics, Chinese Academy of Sciences https://orcid.org/0000-0003-18514803

\section{Article}

Keywords: high-efficiency lithium-sulfur (Li-S) batteries, batteries, electrocatalysis, energy transfer

Posted Date: January 29th, 2021

DOI: https://doi.org/10.21203/rs.3.rs-150414/v1

License: (c) (i) This work is licensed under a Creative Commons Attribution 4.0 International License.

Read Full License 


\section{Abstract}

High-efficiency lithium-sulfur (Li-S) batteries depend on advanced electrode structure that can attain high sulfur utilization at lean-electrolyte and limited lithium. Herein, a twinborn holey $\mathrm{Nb}_{4} \mathrm{~N}_{5}-\mathrm{Nb}_{2} \mathrm{O}_{5}$ heterostructure is designed as a dual-functional host for both redox-kinetics-accelerated sulfur cathode and dendrite-inhibited Li anode simultaneously for long-cycling and lean-electrolyte Li-S full batteries. Benefiting from the accelerative polysulfides anchoring-diffusion converting efficiency and electronicconducting properties of $\mathrm{Nb}_{4} \mathrm{~N}_{5}-\mathrm{Nb}_{2} \mathrm{O}_{5}$, polysulfide-shutting is significantly alleviated. Meanwhile, the lithiophilic nature of holey $\mathrm{Nb}_{4} \mathrm{~N}_{5}-\mathrm{Nb}_{2} \mathrm{O}_{5}$ is applied as ion-redistributor for homogeneous Li-ion deposition. Taking advantage of these merits, the Li-S full batteries present the excellent electrochemical properties, including a minimum capacity decay of $0.025 \%$ per cycle, and a high areal-capacity of 5.0

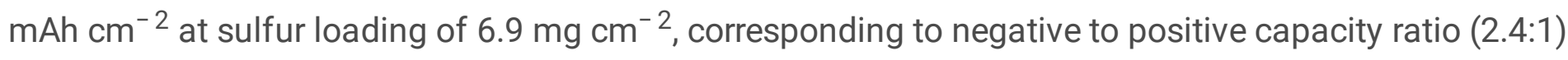
and electrolyte to sulfur ratio $\left(5.1 \mu \mathrm{mg}^{-1}\right)$. Therefore, this work opens a new avenue for boosting highperformances Li-S batteries towards practical applications.

\section{Introduction}

The growing demands for both hand-held electronics and electric vehicles have promoted the exploration of high-energy-density rechargeable batteries over $400 \mathrm{Wh} \mathrm{kg}^{-11}$. Lithium-sulfur (Li-S) batteries with exceptional theoretical energy density $\left(\sim 2500 \mathrm{Wh} \mathrm{kg}^{-1}\right)$, coupled with highly reversible and efficient reactions at the sulfur cathode-electrolyte interface (solid sulfur-soluble lithium polysulfides-insoluble $\mathrm{Li}_{2} \mathrm{~S}$ ) and lithium ( $\mathrm{Li}$ ) anode-electrolyte (lithium striping-plating) are one of the most appealing battery techniques ${ }^{2}$. Basically, the physicochemical properties of the designed electrode host materials significantly influence the reversibility and kinetics of the heterogeneous reaction of Li-S batteries. In addition, the capacity degradations resulting from the irreversible lithium polysulfides (LiPSs) "shuttle effect" on the sulfur cathode, and safety concern deriving from huge volume change and uncontrollable dendrite-forming on the Li metal anode, have severely impeded the commercial generalization ${ }^{3}$. In this regard, a low electrolyte-to-sulfur (E/S) ratio $\left(<6 \mu \mathrm{L} \mathrm{mg}^{-1}\right)$ and low negative to positive (N/P) capacity ratio $(<5)$ under high sulfur loading $\left(>5 \mathrm{mg} \mathrm{cm}^{-2}\right)$ are required for practical Li-S batteries ${ }^{4}$.

For the cathode, intensive efforts have been devoted to effectively confine the original sulfur particles, soluble polysulfides and final solid discharged products via physical and chemical immobilization. The polar materials, especially with catalytic effect, such as metal oxides ${ }^{5}$, sulfides ${ }^{6}$, phosphides $^{7}$, nitrides ${ }^{8}$ and functional carbons ${ }^{9}$, have shown improved electrical performance of sulfur electrodes by enhancing the reaction kinetics and chemical conversion of $\mathrm{LiPSs}^{10}$. Although with great progress, implementing high electrical conductivity, strong adsorption and abundant catalytic sites simultaneously from a single electrode remains chanllenging ${ }^{11}$. Recently, constructing heterostructure sulfur host by the surface and interface engineering presents the most ideal route to achieve LiPSs chemical adsorption, promote electron and charge transfer at interfaces and improve their surface redox kinetics LiPSs regulation ${ }^{12}$. 
Apart from sulfur cathode, various strategies have been explored for modifying the Li metal anodes since the fully assembled Li-S batteries strongly depend on the synergy between sulfur and Li electrodes. For instance, they include the engineering of artificial protection layers ${ }^{13}$, optimizing the electrolytes with additives ${ }^{14}$, using high-surface-area 3D conductive scaffolds ${ }^{15}$, and developing solid-state or polymer electrolytes ${ }^{16}$. However, the inhomogeneous Li ion flux distribution and mass transfers, especially at high current density still emerge during the repeated Li plating and stripping process, which could not fully prohibit the formation of $\mathrm{Li}$ dendrites and dead $\mathrm{Li}^{17}$. In addition, a lithiophilic matrix led to a certain threshold of Li deposition on the lithiophilic surface, hence resulting in the growth of dendrites ${ }^{18,19,20,21}$. To overcome this issue, nanoporous structures such as vertical microchannels ${ }^{22}$, aligned holey nanosheets ${ }^{17}$ and 3D structure containing nanopore ${ }^{23}$ serving as ion redistributors have been proposed to homogenize Li-ion flux on the electrolyte-electrode interface for dendrite-free Li anodes. In short, rational construction of a lithiophilic heterostructured material integrating precise nanoporous surface and interface engineering for both sulfur host and Li metal anode is promising for boosting the performance of Li-S batteries.

Herein, we designed a holey 2D Nb${ }_{4} \mathrm{~N}_{5}-\mathrm{Nb}_{2} \mathrm{O}_{5}$ heterostructure as a dual-functional host material for both sulfur cathode $\left(\mathrm{Nb}_{4} \mathrm{~N}_{5}-\mathrm{Nb}_{2} \mathrm{O}_{5} / \mathrm{S}\right)$ and $\mathrm{Li}$ anode $\left(\mathrm{Nb}_{4} \mathrm{~N}_{5}-\mathrm{Nb}_{2} \mathrm{O}_{5} / \mathrm{Li}\right)$. Such a bibasic host integrated strong chemisorptive $\mathrm{Nb}_{2} \mathrm{O}_{5}$ and high conductive $\mathrm{Nb}_{4} \mathrm{~N}_{5}$, simultaneously facilitating high trapping efficiency and fast electron transportation of LiPSs conversion on the heterostructure surface. As for the anode scaffold, the holey lithiophilic $\mathrm{Nb}_{4} \mathrm{~N}_{5}-\mathrm{Nb}_{2} \mathrm{O}_{5}$ heterostructure greatly reduced the deposition current density and enabled homogeneous Li-ion distribution, hence suppressing Li dendrite formation. Based on that, a meticulously designed Li-S full battery configuration was achieved with super-rate capability of 1163 mAh $\mathrm{g}^{-1}$ at $3 \mathrm{C}$ and remarkable cycle stability over 1000 cycles (capacity degradation rate of $0.025 \%$ per cycle). Furthermore, a promising areal capacity up to $5.0 \mathrm{mAh} \mathrm{cm} \mathrm{cm}^{-2}$ for 200 cycles with a high sulfur loading ( $6.9 \mathrm{mg} \mathrm{cm}^{-2}$ ) was achieved for the $\mathrm{Nb}_{4} \mathrm{~N}_{5}-\mathrm{Nb}_{2} \mathrm{O}_{5} / \mathrm{Li} \| \mathrm{Nb}_{4} \mathrm{~N}_{5}-\mathrm{Nb}_{2} \mathrm{O}_{5} / \mathrm{S}$ batteries. Thus, this work presents a novel design of advanced host to comprehensively address the obstacles in sulfur cathode and Li anode towards the high-performance Li-S batteries.

\section{Results}

Fabrication and Characterization of $\mathrm{Nb}_{4} \mathrm{~N}_{5}-\mathrm{Nb}_{2} \mathrm{O}_{5}$ Heterostructure. The desirable properties of electrocatalysts for fast conversion of LiPSs are dominated by three main factors: (a) high adsorption ability to anchor LiPSs, (b) rich catalytic active sites to enhance the conversion kinetics, and (c) good electrical conductivity for effectively electron transfer 24,25 . Based on that, $2 \mathrm{D} \mathrm{Nb}{ }_{4} \mathrm{~N}_{5}-\mathrm{Nb}_{2} \mathrm{O}_{5}$ heterostructure integrates those properties with synergetic effect of $\mathrm{Nb}_{2} \mathrm{O}_{5}$ and $\mathrm{Nb}_{4} \mathrm{~N}_{5}$. To be more specific, the bare $\mathrm{Nb}_{2} \mathrm{O}_{5}$ possesses desirable chemical adsorption, which is necessary for the LiPSs. However, electrical conductivity is not high for electrons transfer ${ }^{26}$. In contrast, polar $\mathrm{Nb}_{4} \mathrm{~N}_{5}$ with superior electrical conductivity facilitates efficient conversion of LiPSs, but poor affinity of the LiPSs on its surface ${ }^{27}$. Therefore, the novel design of $\mathrm{Nb}_{4} \mathrm{~N}_{5}-\mathrm{Nb}_{2} \mathrm{O}_{5}$ heterostructure by coupling the merits of highly 
adsorptive $\mathrm{Nb}_{2} \mathrm{O}_{5}$ and conductive $\mathrm{Nb}_{4} \mathrm{~N}_{5}$ can enable a fast nucleation and conversion of the LiPSs. Consequently, the LiPSs shuttling is effectively confined and the utilization of sulfur is greatly promoted (Fig. 1a).

The $2 \mathrm{D} \mathrm{Nb}{ }_{4} \mathrm{~N}_{5}-\mathrm{Nb}_{2} \mathrm{O}_{5}$ heterostructures were prepared by a facile hydrothermal and subsequent ammonia annealing treatment. The scanning electron microscope (SEM) image showed uniform flower morphology, composed of holey nanosheets (Fig. 1b and Supplementary Fig. 1). Significantly, the composition of $\mathrm{Nb}_{4} \mathrm{~N}_{5}-\mathrm{Nb}_{2} \mathrm{O}_{5}$ heterostructure could be adjusted by nitriding temperature and time. As a result, $\mathrm{Nb}_{2} \mathrm{O}_{5}-\mathrm{Nb}_{4} \mathrm{~N}_{5}$ heterostructures with the ratio of around 1:1 (Supplementary Table 1) were successfully obtained (Fig. 1c). The high-resolution transmission electron microscope (TEM) images illustrated that the lattice spacings were $0.25 \mathrm{~nm}$ and $0.39 \mathrm{~nm}$, matching the (211) planes of $\mathrm{Nb}_{4} \mathrm{~N}_{5}$ (Supplementary Fig. 2) and (001) planes of $\mathrm{Nb}_{2} \mathrm{O}_{5}$ (Supplementary Fig. 3), respectively. More importantly, a heterostructured interface between them was clearly observed (Fig. 1d). Such an interface was not only conducive for fast electron transportation, but also improved the adsorption and conversion of LiPSs ${ }^{24}$. In addition, the porous structure was beneficial to offer easy accessibility to LiPSs with rich active sites for the consequent adsorption and catalytic conversion (Fig. 1e and Supplementary Fig. 4). X-ray photoelectron spectroscopy (XPS) further confirmed the existence of $\mathrm{Nb}-\mathrm{O}, \mathrm{Nb}-\mathrm{N}$ bonding configuration (Fig. 1f) ${ }^{28}$. The intact connection and uniform distribution of $\mathrm{Nb}_{2} \mathrm{O}_{5}$ and $\mathrm{Nb}_{4} \mathrm{~N}_{5}$ were verified by the energy-dispersive spectrometry element mapping results (Fig. 1g).

Electrocatalytic and Adsorption Effects of $\mathrm{Nb}_{4} \mathrm{~N}_{5}-\mathrm{Nb}_{2} \mathrm{O}_{5}$ Heterostructure. First-principle calculations were performed to disclose the chemical interaction of LiPSs $\left(\mathrm{Li}_{2} \mathrm{~S}_{4}\right.$ was chosen as the protype for modelling) with $\mathrm{Nb}_{2} \mathrm{O}_{5}$ and $\mathrm{Nb}_{4} \mathrm{~N}_{5}$ configurations. The adsorption energies of $\mathrm{Li}_{2} \mathrm{~S}_{4}$ on $\mathrm{Nb}_{4} \mathrm{~N}_{5}$ (211) and $\mathrm{Nb}_{2} \mathrm{O}_{5}(001)$ surfaces were $-4.8 \mathrm{eV}$ and $-6.2 \mathrm{eV}$ respectively, indicating that $\mathrm{Nb}_{2} \mathrm{O}_{5}$ had higher adsorption affinity for LiPSs ${ }^{29}$. Further, the superior conductivity of $\mathrm{Nb}_{4} \mathrm{~N}_{5}$ guaranteed the fast diffusion of LiPSs from $\mathrm{Nb}_{2} \mathrm{O}_{5}$ surface to $\mathrm{Nb}_{4} \mathrm{~N}_{5}$ surface across the interfacial migration between them (Fig. $2 \mathrm{a}, \mathrm{b}$ ). As a result, $\mathrm{Nb}_{4} \mathrm{~N}_{5}-\mathrm{Nb}_{2} \mathrm{O}_{5}$ could efficiently enhance the electrochemical reactions and accelerate the oxidation conversion of dissolved LiPSs to solid $\mathrm{Li}_{2} \mathrm{~S}$ in the discharge process, which ensured a discharging/charging loop process with excellent reversibility (Fig. 2c).

We selected the $\mathrm{Nb}_{4} \mathrm{~N}_{5}-\mathrm{Nb}_{2} \mathrm{O}_{5}$ heterostructure (with the ratio of around 1:1) as the model catalyst representation for deducing the reaction mechanism of electrocatalysis in corresponding Li-S batteries. $\mathrm{Nb}_{4} \mathrm{~N}_{5}-\mathrm{Nb}_{2} \mathrm{O}_{5}$ mixture $\left(\mathrm{Nb}_{4} \mathrm{~N}_{5}-\mathrm{Nb}_{2} \mathrm{O}_{5}\right.$ mix with the ratio of 1:1), bare $\mathrm{Nb}_{4} \mathrm{~N}_{5}$ and bare $\mathrm{Nb}_{2} \mathrm{O}_{5}$ were also selected for comparison. In order to confirm the improved redox-reaction kinetics in the liquid-liquid transformation process, cyclic voltammetry (CV) measurement using symmetric batteries based on $\mathrm{Li}_{2} \mathrm{~S}_{6}$ catholyte were employed. The redox current response increased in the order of $\mathrm{Nb}_{2} \mathrm{O}_{5}<\mathrm{Nb}_{4} \mathrm{~N}_{5}<\mathrm{Nb}_{4} \mathrm{~N}_{5}-$ $\mathrm{Nb}_{2} \mathrm{O}_{5}$ mix $<\mathrm{Nb}_{4} \mathrm{~N}_{5}-\mathrm{Nb}_{2} \mathrm{O}_{5}$ heterostructure (Fig. 2d), reflecting that $\mathrm{Nb}_{4} \mathrm{~N}_{5}-\mathrm{Nb}_{2} \mathrm{O}_{5}$ heterostructure possessed better interfacial kinetics ${ }^{30}$. Apart from the liquid-liquid transformation of LiPSs, the polar and conductive heterostructure also played a key role at liquid-solid boundary. A potentiostatic nucleation 
experiment was conducted to understand the electrochemical deposition from LiPSs to solid $\mathrm{Li}_{2} \mathrm{~S}$. Specifically, the capacity $168 \mathrm{mAh} \mathrm{g}^{-1}$ of the precipitated $\mathrm{Li}_{2} \mathrm{~S}$ on $\mathrm{Nb}_{4} \mathrm{~N}_{5}-\mathrm{Nb}_{2} \mathrm{O}_{5}$ heterostructure electrode was much higher than those of $\mathrm{Nb}_{4} \mathrm{~N}_{5}-\mathrm{Nb}_{2} \mathrm{O}_{5}$ mix $\left(132 \mathrm{mAh} \mathrm{g}^{-1}\right), \mathrm{Nb}_{4} \mathrm{~N}_{5}\left(124 \mathrm{mAh} \mathrm{g}^{-1}\right)$, and $\mathrm{Nb}_{2} \mathrm{O}_{5}(88$ mAh $\mathrm{g}^{-1}$ ). Besides, the battery with $\mathrm{Nb}_{4} \mathrm{~N}_{5}-\mathrm{Nb}_{2} \mathrm{O}_{5}$ heterostructure exhibited the highest current density of $0.074 \mathrm{~mA}$, suggesting the role of heterostructure in fast LiPSs trapping and nucleation of $\mathrm{Li}_{2} \mathrm{~S}$ (Fig. 2eh) ${ }^{31}$. Moreover, the sluggish oxidation kinetics of solid $\mathrm{Li}_{2} \mathrm{~S}$ at the charging cycle is the dominant factor for the reduced reversibility of $\mathrm{Li}_{2} \mathrm{~S}$-to-LiPSs interconversion, thus leaving behind unusable electrochemical phases (also called "dead sulfur"). Similarly, kinetic evaluation of $\mathrm{Li}_{2} \mathrm{~S}$ decomposition was conducted by a potentiostatic charging process after full discharge into solid $\mathrm{Li}_{2} \mathrm{~S}$. $\mathrm{Nb}_{4} \mathrm{~N}_{5}-\mathrm{Nb}_{2} \mathrm{O}_{5}$ heterostructure showed an obvious oxidation current peak at $577 \mathrm{~s}$, which was much earlier than those of $\mathrm{Nb}_{4} \mathrm{~N}_{5}-\mathrm{Nb}_{2} \mathrm{O}_{5}$ mix (763 s), $\mathrm{Nb}_{4} \mathrm{~N}_{5}$ (1021 s) and $\mathrm{Nb}_{2} \mathrm{O}_{5}(2620 \mathrm{~s})$. In addition, the improved $\mathrm{Li}_{2} \mathrm{~S}$ dissolution could reduce the deactivation of the catalyst surface and increase the utilization of sulfur ${ }^{32}$. Furthermore, the linear sweep voltammetry (LSV) indicated that $\mathrm{Nb}_{4} \mathrm{~N}_{5}-\mathrm{Nb}_{2} \mathrm{O}_{5}$ heterostructure electrode exhibited highest reaction peak current $\left(0.43 \mathrm{~mA} \mathrm{~cm}^{-2}\right)$ with lowest Tafel slope $\left(89.4 \mathrm{mV} \mathrm{dec}^{-1}\right)$, further demonstrative of the improved kinetics of LiPSs redox reactions (Fig. 2j and Supplementary Fig. 5) ${ }^{33}$.

To study the chemical adsorption behavior of the $\mathrm{Nb}_{4} \mathrm{~N}_{5}-\mathrm{Nb}_{2} \mathrm{O}_{5}$ heterostructure for LiPSs, a visual adsorption test was conducted by adding the same amount $(\sim 5 \mathrm{mg})$ of materials into the $\mathrm{Li}_{2} \mathrm{~S}_{6}$ solution. As shown in Fig. $2 \mathrm{k}$, the solution with $\mathrm{Nb}_{4} \mathrm{~N}_{5}-\mathrm{Nb}_{2} \mathrm{O}_{5}$ heterostructure additive rapidly decolored. The sample with $\mathrm{Nb}_{2} \mathrm{O}_{5}$ showed slightly inferior decoloration phenomenon compared to the heterostructure due to the limited specific area $\left(33.9 \mathrm{~m}^{2} \mathrm{~g}^{-1}\right)$ than that of heterostructure $\left(40.5 \mathrm{~m}^{2} \mathrm{~g}^{-1}\right)$, while the control sample with bare $\mathrm{Nb}_{4} \mathrm{~N}_{5}$ showed minor difference (Fig. 1e and Supplementary Fig. 4). This was consistent with the ultraviolet-visible (UV-vis) absorption and density functional theory (DFT) calculation results. Moreover, the nature of the interaction between LiPSs and $\mathrm{Nb}_{4} \mathrm{~N}_{5}-\mathrm{Nb}_{2} \mathrm{O}_{5}$ heterostructure was probed by XPS measurement. In the deconvoluted Li 1s spectrum, two obvious peaks at $60.9 \mathrm{eV}$ and 59.7 $\mathrm{eV}$ were observed, corresponding to $\mathrm{Li}-\mathrm{O}$ and Li-N bond (Fig. 2l). Moreover, additional Nb-S peaks (203.7 $\mathrm{eV}, 206.3 \mathrm{eV}$ ) were detected in $\mathrm{Nb} 3 \mathrm{~d}$ XPS spectrum ${ }^{34}$. These results indicated that the $\mathrm{Nb}_{4} \mathrm{~N}_{5}-\mathrm{Nb}_{2} \mathrm{O}_{5}$ heterostructure strongly interacted with LiPSs (Fig. $2 \mathrm{~m}$ ), offering a potential functional material for LiPSs electrocatalysis.

To demonstrate the favorable LiPSs adsorption and electrocatalytic reactivity of $\mathrm{Nb}_{4} \mathrm{~N}_{5}-\mathrm{Nb}_{2} \mathrm{O}_{5}$ heterostructure on the sulfur reactions, the half-cell configurations were fabricated with a Li metal foil as anode and $\mathrm{Nb}_{4} \mathrm{~N}_{5}-\mathrm{Nb}_{2} \mathrm{O}_{5}$ heterostructure, $\mathrm{Nb}_{4} \mathrm{~N}_{5}-\mathrm{Nb}_{2} \mathrm{O}_{5}$ mix, $\mathrm{Nb}_{4} \mathrm{~N}_{5}$ and $\mathrm{Nb}_{2} \mathrm{O}_{5}$ loaded with sulfur as cathodes respectively to evaluate their electrochemical performance. The $\mathrm{CV}$ curves of all the assembled Li-S batteries showed the typical pair of redox peaks, corresponding to the formation of soluble LiPSs (2.2-2.4 V) and solid $\mathrm{Li}_{2} \mathrm{~S}(2.1-2.0 \mathrm{~V})$. Obviously, the $\mathrm{Nb}_{4} \mathrm{~N}_{5}-\mathrm{Nb}_{2} \mathrm{O}_{5}$ heterostructure exhibited a considerably mitigated electrochemical polarization with the highest current intensity and a good overlap of CV profiles (Fig. 3a and Supplementary Fig. 6), indictive of enhanced redox kinetics and sufficient 
utilization of the LiPSs along $\mathrm{Nb}_{4} \mathrm{~N}_{5}-\mathrm{Nb}_{2} \mathrm{O}_{5}$ heterostructure ${ }^{35}$. Moreover, the substantial improvement of the charge transfer from the $\mathrm{Nb}_{4} \mathrm{~N}_{5}-\mathrm{Nb}_{2} \mathrm{O}_{5}$ heterostructure was further verified by electrochemical impedance spectroscopy (EIS). Obviously, the charge-transfer resistance $\left(R_{c t}\right)$ of $\mathrm{Nb}_{4} \mathrm{~N}_{5}-\mathrm{Nb}_{2} \mathrm{O}_{5}$ electrode $\left(18.8 \Omega\right.$ ) was lower compared with the $\mathrm{Nb}_{4} \mathrm{~N}_{5}-\mathrm{Nb}_{2} \mathrm{O}_{5}$ mix $(24.5 \Omega), \mathrm{Nb}_{4} \mathrm{~N}_{5}(64.0 \Omega)$ and $\mathrm{Nb}_{2} \mathrm{O}_{5}(111.8 \Omega)$, implying better interfacial kinetics of $\mathrm{Nb}_{4} \mathrm{~N}_{5}-\mathrm{Nb}_{2} \mathrm{O}_{5}$ heterostructure (Fig. 3b) ${ }^{36}$.

Subsequently, the cyclability was tested at a constant current density of $0.5 \mathrm{C}$ to evaluate the catalytic ability of the cathodes. The initial capacity of the cathode with $\mathrm{Nb}_{4} \mathrm{~N}_{5}-\mathrm{Nb}_{2} \mathrm{O}_{5}$ heterostructure was 1108 mAh g ${ }^{-1}$, significantly higher than those of $\mathrm{Nb}_{4} \mathrm{~N}_{5}-\mathrm{Nb}_{2} \mathrm{O}_{5}$ mix $\left(1015 \mathrm{mAh} \mathrm{g}^{-1}\right), \mathrm{Nb}_{4} \mathrm{~N}_{5}\left(975 \mathrm{mAh} \mathrm{g}^{-1}\right)$ and $\mathrm{Nb}_{2} \mathrm{O}_{5}\left(903 \mathrm{mAh} \mathrm{g}^{-1}\right.$ ) (Fig. 3c and Supplementary Fig. 7). In addition, the cathode with $\mathrm{Nb}_{4} \mathrm{~N}_{5}-\mathrm{Nb}_{2} \mathrm{O}_{5}$ heterostructure showed smaller polarization $(150 \mathrm{mV})$ than those of $\mathrm{Nb}_{4} \mathrm{~N}_{5}-\mathrm{Nb}_{2} \mathrm{O}_{5}$ mix $(213 \mathrm{mV}), \mathrm{Nb}_{4} \mathrm{~N}_{5}$ $(210 \mathrm{mV})$ and $\mathrm{Nb}_{2} \mathrm{O}_{5}(259 \mathrm{mV})$ (Supplementary Fig. 8), suggesting the improved redox reaction ${ }^{37}$. Apart from that, the $\mathrm{Nb}_{4} \mathrm{~N}_{5}-\mathrm{Nb}_{2} \mathrm{O}_{5}$ heterostructure based sulfur cathode retained a high capacity of $1021 \mathrm{mAh}$ $\mathrm{g}^{-1}$ and high Coulombic efficiency 100\% over 120 cycles, with an ultralow capacity decay rate of $0.07 \%$. Impressively, a high capacity of $942 \mathrm{mAh} \mathrm{g}^{-1}$ was sustained more than 500 cycles, (Supplementary Fig. 9), which suggested that the shutting effect of LiPSs was significantly suppressed as the strong chemisorption. In contrast, only $760 \mathrm{mAh} \mathrm{g}^{-1}$ for $\mathrm{Nb}_{4} \mathrm{~N}_{5}-\mathrm{Nb}_{2} \mathrm{O}_{5}$ mix (capacity degradation rate of $0.18 \%$ ), $681 \mathrm{mAh} \mathrm{g}^{-1}$ for $\mathrm{Nb}_{4} \mathrm{~N}_{5}$ (capacity degradation rate of $0.21 \%$ ), and $443 \mathrm{mAh} \mathrm{g}^{-1}$ for $\mathrm{Nb}_{2} \mathrm{O}_{5}$ (capacity degradation rate of $0.42 \%$ ) were remained at 120 cycles (Fig. $3 \mathrm{~d}$ ). The rate performances from $0.5 \mathrm{C}$ to 10 $\mathrm{C}$ were further tested to evaluate the superior kinetics of LiPSs conversion. As shown in Fig. 3e, the $\mathrm{Nb}_{4} \mathrm{~N}_{5}-\mathrm{Nb}_{2} \mathrm{O}_{5}$ heterostructure based sulfur cathode presented superior rate response and exceptional reversibility compared with those of the reference electrodes. Specifically, when cycled at step current rates $(0.5,1,2,3,5$ and $8 \mathrm{C})$, such a heterostructure electrode could deliver discharge capacities of 1159 , 1095, 1063, 1028, 968 and 899 mAh g $^{-1}$ with nearly 100\% Coulombic efficiency, respectively. Even increasing high current rate to $10 \mathrm{C}$, an excellent reversible capacity (844 $\mathrm{mAh} \mathrm{g}^{-1}$ ) was remained. In contrast, the batteries employing $\mathrm{Nb}_{4} \mathrm{~N}_{5}-\mathrm{Nb}_{2} \mathrm{O}_{5}$ mix, bare $\mathrm{Nb}_{4} \mathrm{~N}_{5}$ and $\mathrm{Nb}_{2} \mathrm{O}_{5}$ showed much inferior capacities of 675,225 and $141 \mathrm{mAh} \mathrm{g}^{-1}$ under the rate of $10 \mathrm{C}$ (Supplementary Fig. 10). Remarkably, the ultrahigh rate capability coupled with ultralow capacity decay rate, has been raraly reported in the former heterostructure materials-based Li-S batteries (Supplementary Table S2), such as MoN-VN (636 mAh g-1 at $2 \mathrm{C}$ with $0.06 \%$ decay rate $)^{38}, \mathrm{VO}_{2}-\mathrm{VN}\left(587 \mathrm{mAh} \mathrm{g}^{-1} \text { at } 5 \mathrm{C} \text { with } 0.06 \% \text { decay rate }\right)^{24}$ and $\mathrm{TiO}_{2}-\mathrm{Ni}_{3} \mathrm{~S}_{2}$ (534 mAh g-1 at $5 \mathrm{C}$ with $0.04 \%$ decay rate) ${ }^{32}$. In addition, the maximum power density $\left(12010 \mathrm{~W} \mathrm{~kg}^{-1}\right)$ and energy density ( $1628 \mathrm{Wh} \mathrm{kg}^{-1}$ ) calculated by the whole mass of cathode are competitive to majority recent reports (Supplementary Fig. 11), such as VN-S $\left(3058 \mathrm{~W} \mathrm{~kg}^{-1}, 1014 \mathrm{Wh} \mathrm{kg}^{-1}\right)^{39}, \mathrm{TiS}_{2}-\mathrm{S}\left(3058 \mathrm{~W} \mathrm{~kg}^{-}\right.$ $\left.1,1014 \mathrm{Wh} \mathrm{kg}^{-1}\right)^{40}$ and ZnS-S $\left(3863 \mathrm{~W} \mathrm{~kg}^{-1}, 1396 \mathrm{Wh} \mathrm{kg}^{-1}\right)^{41}$.

Lithium Dendrite Suppression of $\mathrm{Nb}_{4} \mathrm{~N}_{5}-\mathrm{Nb}_{2} \mathrm{O}_{5}$ Heterostructure. In fact, the performance of Li-S batteries is severely limited by both unacceptable Li dendrite formation and unstable solid electrolyte 
interphase $(\mathrm{SEI})^{42}$. In particular, the uneven Li-ion flux during the repeating plating/stripping is regard as the main reason causing the safety risks and short lifetime of Li metal anode ${ }^{43}$. Our $2 \mathrm{D} \mathrm{Nb} \mathrm{N}_{4} \mathrm{~N}_{5}-\mathrm{Nb}_{2} \mathrm{O}_{5}$ heterostructure with dominating hole (1.7-3.5 nm) (Fig. 4a and Supplementary Fig. 12) is expected to benefit the Li-ion redistributor for improving the uniformity of Li-ion flux (Fig. 4b). Besides, the abundant and homogeneously distributed $\mathrm{N}$ and $\mathrm{O}$ element on the $\mathrm{Nb}_{4} \mathrm{~N}_{5}-\mathrm{Nb}_{2} \mathrm{O}_{5}$ surface can be regarded as lithiophilic sites (binding energy with $\mathrm{Li}$ atom: $-3.5 \mathrm{eV}$ for $\mathrm{Nb}_{2} \mathrm{O}_{5}$ and $-5.3 \mathrm{eV}$ for $\mathrm{Nb}_{4} \mathrm{~N}_{5}$ ) to guide the uniform Li nucleation (Supplementary Fig. 13 and Supplementary Fig. 14) ${ }^{44}$. Half-cell configurations paired with $\mathrm{Li}$ foil as counter electrode were developed firstly to explore the reversibility of $\mathrm{Nb}_{4} \mathrm{~N}_{5}-\mathrm{Nb}_{2} \mathrm{O}_{5}$ electrodes. For comparison, the bare $\mathrm{Cu}$ electrode was also assembled. After pre-cycling between 0.01-1 V for 4 cycles to stabilize the SEI film and clean impurity (Supplementary Fig. 15 ) ${ }^{45}$, the $\mathrm{Nb}_{4} \mathrm{~N}_{5}-\mathrm{Nb}_{2} \mathrm{O}_{5}$ showed significantly improved Coulombic efficiency of $99.9 \%$ with a steady voltage hysteresis ( $53 \mathrm{mV})$ for 300 cycles than the bare Cu foil electrode ( $58.6 \%$ for 16 cycles) at $0.5 \mathrm{~mA} \mathrm{~cm}^{-2}$ for tripping/plating capacity of $0.5 \mathrm{mAh} \mathrm{cm}^{-2}$ (Fig. 4c and Supplementary Fig. 16). Impressively, ultralong cycling lifespan of $1400 \mathrm{~h}$ coupled with high average Coulombic efficiency of $99.7 \%$ was enabled at $0.5 \mathrm{~mA} \mathrm{~cm}^{-2}$ without dendrite growth (Supplementary Fig. 17). In addition, the voltage dropped sharply to $-174 \mathrm{mV}\left(v s . \mathrm{Li}^{+} / \mathrm{Li}\right)$ at the $\mathrm{Li}$ nucleation stage on $\mathrm{Cu}$ foil electrode, while the voltage curve of $\mathrm{Nb}_{4} \mathrm{~N}_{5}-\mathrm{Nb}_{2} \mathrm{O}_{5}$ electrode exhibited much smoother voltage dip with a smaller nucleation overpotential of only $56 \mathrm{mV}$ (Fig. $4 \mathrm{~d}$ ). The results indicated the high lithiophilic property of the $\mathrm{Nb}_{4} \mathrm{~N}_{5}-\mathrm{Nb}_{2} \mathrm{O}_{5}$ surface ${ }^{46}$. Then, the long cycling stability of $\mathrm{Nb}_{4} \mathrm{~N}_{5}-\mathrm{Nb}_{2} \mathrm{O}_{5}$ electrode was evaluated by the Li||Li symmetrical configuration. With the pre-stored capacity of $1 \mathrm{mAh} \mathrm{cm} \mathrm{cm}^{-2}$ at $1 \mathrm{~mA} \mathrm{~cm}{ }^{-2}$, excellent cycling stability (1000 h) with highly stable overpotential ( $10.5 \mathrm{mV}$ ) was highlighted for $\mathrm{Nb}_{4} \mathrm{~N}_{5}-\mathrm{Nb}_{2} \mathrm{O}_{5} / \mathrm{Li} \mid \mathrm{Nb}_{4} \mathrm{~N}_{5}-\mathrm{Nb}_{2} \mathrm{O}_{5} / \mathrm{Li}$ symmetric batteries. However, a limited cycle lifespan with obvious fluctuant overpotential ( $162 \mathrm{mV}$ for $102 \mathrm{~h}$ ) was observed for the Cu-Li\|Cu-Li symmetric batteries (Fig. 4e, f). Even at high current density of $3 \mathrm{~mA} \mathrm{~cm}^{-2}$ and large plating capacity of $3 \mathrm{mAh} \mathrm{cm}{ }^{-2}$, the $\mathrm{Nb}_{4} \mathrm{~N}_{5}-\mathrm{Nb}_{2} \mathrm{O}_{5} / \mathrm{Li}$ based anode could also exhibit long cycling life more than $900 \mathrm{~h}$ with a stable voltage hysteresis of $\sim 11.0 \mathrm{mV}$ (Fig. $4 \mathrm{~g}$ and Supplementary Fig. 18). SEM characterizations were conducted to clearly elucidate the Li deposition morphology after cycling. For the $\mathrm{Cu} / \mathrm{Li}$ electrode, the cavities and islands were formed on the surface after Li plating and striping at $1 \mathrm{~mA}$ $\mathrm{cm}^{-2}$ (Supplementary Fig. 19). As for the $\mathrm{Nb}_{4} \mathrm{~N}_{5}-\mathrm{Nb}_{2} \mathrm{O}_{5} / \mathrm{Li}$ anode, no obvious "dead Li" and Li dendrite were observed after cycling (Fig. $4 \mathrm{~h}$ and Supplementary Fig. 20), indicative of the homogeneous $\mathrm{Li}$ deposition, due to the uniform distribution of $\mathrm{Li}$ ions by the holey and lithiophilic $\mathrm{Nb}_{4} \mathrm{~N}_{5}-\mathrm{Nb}_{2} \mathrm{O}_{5}$ nanosheets.

\section{Discussion}

Lithium Dendrite Suppression of $\mathrm{Nb}_{4} \mathrm{~N}_{5}-\mathrm{Nb}_{2} \mathrm{O}_{5}$ Heterostructure. Based on the great advantages of $\mathrm{Nb}_{4} \mathrm{~N}_{5}-\mathrm{Nb}_{2} \mathrm{O}_{5}$ heterostructure for both $\mathrm{S}$ cathode and $\mathrm{Li}$ anode, the as-developed $\mathrm{Nb}_{4} \mathrm{~N}_{5}-\mathrm{Nb}_{2} \mathrm{O}_{5} / \mathrm{Li}$ (with an excess $\mathrm{Li}$ of $50 \%$ ) and $\mathrm{Nb}_{4} \mathrm{~N}_{5}-\mathrm{Nb}_{2} \mathrm{O}_{5} / \mathrm{S}$ were paired for full-battery configuration $\left(\mathrm{Nb}_{4} \mathrm{~N}_{5}-\mathrm{Nb}_{2} \mathrm{O}_{5} / \mathrm{Li}|| \mathrm{Nb}_{4} \mathrm{~N}_{5}-\right.$ $\mathrm{Nb}_{2} \mathrm{O}_{5} / \mathrm{S}$ ) (Fig. 5a). Impressively, a much-improved rate performance was realized with a high discharged 
capacity $\left(1163 \mathrm{mAh} \mathrm{g}^{-1}\right)$ and well-maintained two-plateau profiles at $3 \mathrm{C}$ (nearly $87 \%$ capacity retention ratio of the capacity at $0.3 \mathrm{C}, 1348 \mathrm{mAh} \mathrm{g}^{-1}$ ) (Fig. 5b, c), suggesting the fast reaction kinetics in the obtained full batteries. The $\mathrm{Nb}_{4} \mathrm{~N}_{5}-\mathrm{Nb}_{2} \mathrm{O}_{5} / \mathrm{Li} \| \mathrm{Nb}_{4} \mathrm{~N}_{5}-\mathrm{Nb}_{2} \mathrm{O}_{5} / \mathrm{S}$ full battery could deliver a stable cycling capacity of $856 \mathrm{mAh} \mathrm{g}^{-1}$ under the sulfur loading of $5.4 \mathrm{mg} \mathrm{cm}^{-2}$ at $0.3 \mathrm{C}$ (Supplementary Fig. 21). Moreover, a high sulfur loading $\left(6.9 \mathrm{mg} \mathrm{cm}^{-2}\right)$, corresponding to N/P (2.4:1) and E/S $\left(5.1 \mu \mathrm{mg}^{-1}\right)$, respectively, was successfully assembled. As indicated in Fig. 5d, a practicable areal capacity (5.0 mAh $\mathrm{cm}^{-2}$ ) with nearly $100 \%$ Coulombic efficiency was attained for 200 cycles, which exceeded the common Li-ion batteries ( $4 \mathrm{mAh} \mathrm{cm}^{-2}$ ). In addition, a favorable capacity of $1354 \mathrm{mAh} \mathrm{g}^{-1}$ could be achieved with excellent cycle stability for 120 cycles for the $\mathrm{Nb}_{4} \mathrm{~N}_{5}-\mathrm{Nb}_{2} \mathrm{O}_{5} / \mathrm{Li}|| \mathrm{Nb}_{4} \mathrm{~N}_{5}-\mathrm{Nb}_{2} \mathrm{O}_{5} / \mathrm{S}$ at an elevated temperature of $50{ }^{\circ} \mathrm{C}$ (Fig. 5e), demonstrative of high temperature affordability. Encouragingly, the assembled $\mathrm{Nb}_{4} \mathrm{~N}_{5}-\mathrm{Nb}_{2} \mathrm{O}_{5} / \mathrm{Li} \| \mathrm{Nb}_{4} \mathrm{~N}_{5}-\mathrm{Nb}_{2} \mathrm{O}_{5} / \mathrm{S}$ batteries could keep yellow LED constantly lit for $2 \mathrm{~h}$ (Supplementary Fig. 22), highlighting the potential value in practical application. In addition, in situ and in operando XRD showed the efficient conversion of $\mathrm{S}_{8}$ into short chained solid product $\mathrm{Li}_{2} \mathrm{~S}$ during the transition to low voltage and vice versa (Fig. 5f). Which further indicated that the $\mathrm{Nb}_{4} \mathrm{~N}_{5}-\mathrm{Nb}_{2} \mathrm{O}_{5}$ heterostructure facilitated efficient electron transfer and promoted the $\mathrm{Li}_{2} \mathrm{~S}$ nucleation and dissolution during cycling, which ensured the minimization of LiPSs shuttle. Most importantly, the full batteries showed an exceptionally low fading rate of only $0.025 \%$ during 1000 cycles with high maintaining capacity of $1136 \mathrm{mAh} \mathrm{g}^{-2}$ (Fig. $5 \mathrm{~g}$ and Supplementary Fig. 23). Also, our assembled batteries were superior to a majority of the most advanced Li-S full batteries (Supplementary Table S3), such as mesoporous carbon $\left(6.9 \mathrm{mg} \mathrm{cm}^{-2}, 607 \mathrm{mAh} \mathrm{g}^{-1} \text { at 1C, } 0.125 \% \text { decay rate }\right)^{48}$, TiN-VN $\left(5.6 \mathrm{mg} \mathrm{cm}^{-2}, 650\right.$ $\mathrm{mAh} \mathrm{g} \mathrm{g}^{-1}$ at $5 \mathrm{C}, 0.051 \%$ decay rate $)^{21}$ and graphite foam $\left(2.6 \mathrm{mg} \mathrm{cm}^{-2}, 950 \mathrm{mAh} \mathrm{g}^{-1}\right.$ at $3 \mathrm{C}, 0.057 \%$ decay rate $)^{49}$. Overall, the great advantage of our full battery showcases the potential of $2 \mathrm{D} \mathrm{Nb} \mathrm{N}_{5}-\mathrm{Nb}_{2} \mathrm{O}_{5}$ heterostructure for advanced energy storage equipment in the future.

In summary, a long-cycling, high capaicty, and superior rate Li-S full battery was developed by adopting $2 \mathrm{D}$ holey $\mathrm{Nb}_{4} \mathrm{~N}_{5}-\mathrm{Nb}_{2} \mathrm{O}_{5}$ heterostructure as difunctional host for shuttling-inhibited sulfur cathode and dendrite-suppressed $\mathrm{Li}$ anode. The jointed merits of strong anchoring $\left(\mathrm{Nb}_{2} \mathrm{O}_{5}\right)$ and electronic conducting $\left(\mathrm{Nb}_{4} \mathrm{~N}_{5}\right)$ efficiently complete the immobilization-diffusion-conversion of LiPSs, hence successfully suppressing the LiPSs shuttling and facilitating their reaction kinetics. In addition, remarkably reduced effective deposition current density and evenly dispersed Li-ion flux were realized by the lithiophilic $\mathrm{Nb}_{4} \mathrm{~N}_{5}-\mathrm{Nb}_{2} \mathrm{O}_{5}$ ion redistributor. As a result, the constructed $\mathrm{Nb}_{4} \mathrm{~N}_{5}-\mathrm{Nb}_{2} \mathrm{O}_{5} / \mathrm{Li} \| \mathrm{Nb}_{4} \mathrm{~N}_{5}-\mathrm{Nb}_{2} \mathrm{O}_{5} / \mathrm{S}$ batteries showed impressive electrochemical performance including an excellent capacity retention with ultralow capacity fading rate of $0.025 \%$ for 1000 cycles and a remarkable area capacity of $5.0 \mathrm{mAh} \mathrm{cm} \mathrm{cm}^{-2}$ at high sulfur loading up to $6.9 \mathrm{mg} \mathrm{cm}^{-1}$ and low E/S of $5.1 \mu \mathrm{mg}^{-1}$. The present study provides new perspectives for the design of heterojunction materials for the next-generation practical high energy density Li-S batteries.

\section{Declarations}




\section{Data availability}

The authors declare that all the data supporting the findings of this study are available within the article and its Supplementary Information or from the corresponding author upon reasonable request.

\section{Competing financial interests:}

The authors declare no competing financial interests

\section{Publisher's note}

Springer Nature remains neutral with regard to jurisdictional claims in published maps and institutional affiliations

\section{Author contributions}

Z.-S. W. conceptualized the idea; H.S., J.Q., and C.D. carried out the experimental work; P. L. did the DFT calculation; H.S., P.D., J.W., L.Z., and Z.-S. W. participated in discussion of the data and preparation of the manuscript. All authors discussed the results and commented on the manuscript. All authors have given approval to the final version of the manuscript.

\section{Acknowledgements}

The authors acknowledge financially supported by the National Key R@D Program of China (Grants 2016YBF0100100, and 2016YFA0200200), National Natural Science Foundation of China (Grants 51872283, 21805273, 22005298, 22005297, and 22075279), Liaoning BaiQianWan Talents Program, LiaoNing Revitalization Talents Program (Grant XLYC1807153), Natural Science Foundation of Liaoning Province, Joint Research Fund Liaoning-Shenyang National Laboratory for Materials Science (Grant 20180510038), DICP (DICP ZZBS201708, DICP ZZBS201802, and DICP I202032), DICP\&QIBEBT (Grant DICP\&QIBEBT UN201702), Dalian National Laboratory For Clean Energy (DNL), CAS, DNL Cooperation Fund, CAS (DNL180310, DNL180308, DNL201912, and DNL201915).

\section{References}

1. Kang, K., Meng, Y. S., Bréger, J., Grey, C. P. \& Ceder, G. Electrodes with high power and high capacity for rechargeable lithium batteries. Science 311, 977-980 (2006).

2. Peng, Z. Q., Freunberger, S. A., Chen, Y. H. \& Bruce, P. G. A reversible and higher-rate Li- $\mathrm{O}_{2}$ battery. Science 337, 563-566 (2012).

3. Cao, R., Xu, W., Lv, D., Xiao, J. \& Zhang, J. G. Anodes for rechargeable lithium-sulfur batteries. Adv. Energy Mater. 5, 1402273 (2015).

4. Bhargav, A., He, J., Gupta, A. \& Manthiram, A. Lithium-sulfur batteries: attaining the critical metrics. Joule 4, 285-291 (2020). 
5. Tao, Y. et al. Kinetically-enhanced polysulfide redox reactions by $\mathrm{Nb}_{2} \mathrm{O}_{5}$ nanocrystals for high-rate lithium-sulfur battery. Energy Environ. Sci. 9, 3230-3239 (2016).

6. Zhou, G. M. et al. Catalytic oxidation of $\mathrm{Li}_{2} \mathrm{~S}$ on the surface of metal sulfides for $\mathrm{Li}-\mathrm{S}$ batteries. $P$ Natl Acad Sci USA 114, 840-845 (2017).

7. Zhou, J. et al. Deciphering the modulation essence of $\mathrm{p}$ bands in Co-based compounds on Li-S chemistry. Joule 2, 2681-2693 (2018).

8. Sun, Z. et al. Conductive porous vanadium nitride/graphene composite as chemical anchor of polysulfides for lithium-sulfur batteries. Nat. Commun. 8, 1 (2017).

9. Fu, A. et al. Recent advances in hollow porous carbon materials for lithium-sulfur batteries. Small 15, 1804786 (2019).

10. Yang, H. et al. Alkali-metal sulfide as cathodes toward safe and high-capacity metal ( $\mathrm{M}=\mathrm{Li}, \mathrm{Na}, \mathrm{K})$ sulfur batteries. Adv. Energy Mater. 10, 2001764 (2020).

11. Zhou, L., Danilov, D. L., Eichel, R. A. \& Notten, P. H. Host materials anchoring polysulfides in Li-S batteries reviewed. Adv. Energy Mater. 2001304 (2020).

12. Zhang, Z. W., Peng, H. J., Zhao, M. \& Huang, J. Q. Heterogeneous/homogeneous mediators for highenergy-density lithium-sulfur batteries: progress and prospects. Adv. Funct. Mater. 28, 1707536 (2018).

13. Zhu, B. et al. Poly(dimethylsiloxane) thin film as a stable interfacial layer for high-performance lithium-metal battery anodes. Adv. Mater. 29, 1603755 (2017).

14. Qian J. et al. High rate and stable cycling of lithium metal anode. Nat. Commun. 6, 6362 (2015).

15. Zhang, Y. et al. High-capacity, low-tortuosity, and channel-guided lithium metal anode. Proc. Natl. Acad. Sci. U. S. A. 114, 3584-3589 (2017).

16. Cheng, X. B. et al. A review of solid electrolyte interphases on lithium metal anode. Adv. Sci. 3 , 1500213 (2016).

17. Shi, H. et al. A two-dimensional mesoporous polypyrrole-graphene oxide heterostructure as a dualfunctional ion redistributor for dendrite-free lithium metal anodes. Angew. Chem. Int. Ed. 59, 1214712153 (2020).

18. Yan, K. et al. Selective deposition and stable encapsulation of lithium through heterogeneous seeded growth. Nat. Energy 1, 16010 (2016).

19. Zhang, R. et al. Coralloid carbon fiber-based composite lithium anode for robust lithium metal batteries. Joule 2, 764-777 (2018).

20. Liu, Y. Y. et al. Lithium-coated polymeric matrix as a minimum volume-change and dendrite-free lithium metal anode. Nat. Commun. 7, 10992 (2016)..

21. Yao, Y. et al. A dual-functional conductive framework embedded with TiN-VN heterostructures for highly efficient polysulfide and lithium regulation toward stable Li-S full batteries. Adv. Mater. 32, 1905658 (2019). 
22. Moorthy, B., Kim, J.-H., Lee, H.-W. \& Kim, D. K. Vertically aligned carbon nanotubular structure for guiding uniform lithium deposition via capillary pressure as stable metallic lithium anodes. Energy Storage Mater. 24, 602-609 (2020).

23. Ye, H. et al. Stable Li plating/stripping electrochemistry realized by a hybrid Li reservoir in spherical carbon granules with 3D conducting skeletons. J. Am. Chem. Soc. 139, 5916-5922 (2017).

24. Song, Y. et al. Synchronous immobilization and conversion of polysulfides on a $\mathrm{VO}_{2}-\mathrm{VN}$ binary host targeting high sulfur load Li-S batteries. Energy Environ. Sci. 11, 2620-2630 (2018).

25. Zhou, T. et al. Twinborn $\mathrm{TiO}_{2}$-TiN heterostructures enabling smooth trapping-diffusion-conversion of polysulfides towards ultralong life lithium-sulfur batteries. Energy Environ. Sci. 10, 1694-1703 (2017).

26. Tao, Y. et al. Kinetically-enhanced polysulfide redox reactions by $\mathrm{Nb}_{2} \mathrm{O}_{5}$ nanocrystals for high-rate lithium-sulfur battery. Energy Environ. Sci. 9, 3230-3239 (2016).

27. Ge, W. et al. Conductive cobalt doped niobium nitride porous spheres as an efficient polysulfide convertor for advanced lithium-sulfur batteries. J. Mater. Chem. A 8, 6276-6282 (2020).

28. Cui, $\mathrm{H}$. et al. Niobium nitride $\mathrm{Nb}_{4} \mathrm{~N}_{5}$ as a new high-performance electrode material for supercapacitors. Adv. Sci. 2, 1500126 (2015).

29. Yin, L.-C. et al.Understanding the interactions between lithium polysulfides and $\mathrm{N}$-doped graphene using density functional theory calculations. Nano Energy 25, 203-210 (2016).

30. Li, S. et al. Improve redox activity and cycling stability of the lithium-sulfur batteries via in situ formation of a sponge-like separator modification layer. Int J Energ Res. 44, 4933-4943 (2020).

31. Li, B. Q. et al. Expediting redox kinetics of sulfur species by atomic-scale electrocatalysts in lithiumsulfur batteries. InfoMat 1, 533-541 (2019).

32. Wang, R. et al. Bidirectional catalysts for liquid-solid redox conversion in lithium-sulfur batteries. Adv. Sci. 32, 2000315 (2020).

33. Xu, Z. L. et al. Exceptional catalytic effects of black phosphorus quantum dots in shuttling-free lithium sulfur batteries. Nat. Commun. 9, 4164 (2018).

34. Luo, D. et al. Revealing the rapid electrocatalytic behavior of ultrafine amorphous defective $\mathrm{Nb}_{2} \mathrm{O}_{5-x}$ nanocluster toward superior Li-S performance. ACS Nano 14, 4849-4860 (2020).

35. Liu, D. et al. Catalytic effects in lithium-sulfur batteries: promoted sulfur transformation and reduced shuttle effect. Adv. Sci. 5, 1700270 (2018).

36. Yang, X. et al. Promoting the transformation of $\mathrm{Li}_{2} \mathrm{~S}_{2}$ to $\mathrm{Li}_{2} \mathrm{~S}$ : significantly increasing utilization of active materials for high-sulfur-loading Li-S batteries. Adv. Mater. 31, 1901220 (2019).

37. Tsao, Y. et al. Designing a quinone-based redox mediator to facilitate $\mathrm{Li}_{2} \mathrm{~S}$ oxidation in Li-S batteries. Joule 3, 872-884 (2019).

38. Ye, C. et al. 2D MoN-VN heterostructure to regulate polysulfides for highly efficient lithium-sulfur batteries. Angew. Chem. Int. Ed. 57, 16703-16707 (2018). 
39. He, J. \& Manthiram, A. Long-life, high-rate lithium-sulfur cells with a carbon-free VN host as an efficient polysulfide adsorbent and lithium dendrite inhibitor. Adv. Energy Mater. 10, 1903241 (2020).

40. Huang, X. et al. Sandwich-like ultrathin $\mathrm{TiS}_{2}$ nanosheets confined within N, S codoped porous carbon as an effective polysulfide promoter in lithium-sulfur batteries. Adv. Energy Mater. 9, 1901872 (2019).

41. Xu, J. et al. Promoting lithium polysulfide/sulfide redox kinetics by the catalyzing of zinc sulfide for high performance lithium-sulfur battery. Nano Energy 51, 73-82 (2018).

42. Jin, Y. et al. Self-healing SEl enables full-cell cycling of a silicon-majority anode with a coulombic efficiency exceeding 99.9\%. Energy Environ. Sci. 10, 580-592 (2017).

43. Shen, X. et al. The failure of solid electrolyte interphase on Li metal anode: structural uniformity or mechanical strength? Adv. Energy Mater. 10, 1903645 (2020).

44. Chen, X. et al. Lithiophilicity chemistry of heteroatom-doped carbon to guide uniform lithium nucleation in lithium metal anodes. Sci. Adv. 5, eaau7728 (2019).

45. Liu, S. et al. Crumpled graphene balls stabilized dendrite-free lithium metal anodes. Joule 2, 184-193 (2018).

46. Zhang, R. et al. Lithiophilic sites in doped graphene guide uniform lithium nucleation for dendrite-free lithium metal anodes. Angew. Chem. Int. Ed. 56, 7764-7768 (2017)..

47. Yang, X., Li, X., Adair, K., Zhang, H. \& Sun, X. Structural design of lithium-sulfur batteries: from fundamental research to practical application. Electrochem. Energy Rev. 1, 239-293 (2018).

48. Cao, D. et al. Stable lithium-sulfur full cells enabled by dual functional and interconnected mesocarbon arrays. J. Mater. Chem. A 7, 3289-3297 (2019).

49. Jin, S. et al. Covalently connected carbon nanostructures for current collectors in both the cathode and anode of Li-S batteries. Adv. Mater. 28, 9094-9102 (2016).

\section{Figures}


a Bare $\mathrm{Nb}_{2} \mathrm{O}_{5}$

1. Strong binding

2. Week nucleation

Polysulfide
Bare $\mathrm{Nb}_{4} \mathrm{~N}_{5}$

1. Week binding

2. Strong nucleation

$\mathrm{Li}_{2} \mathrm{~S}$

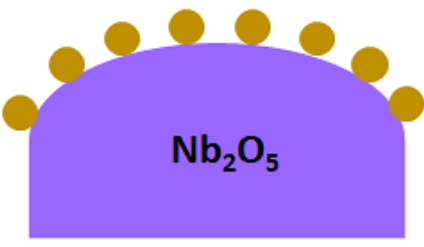

$b$

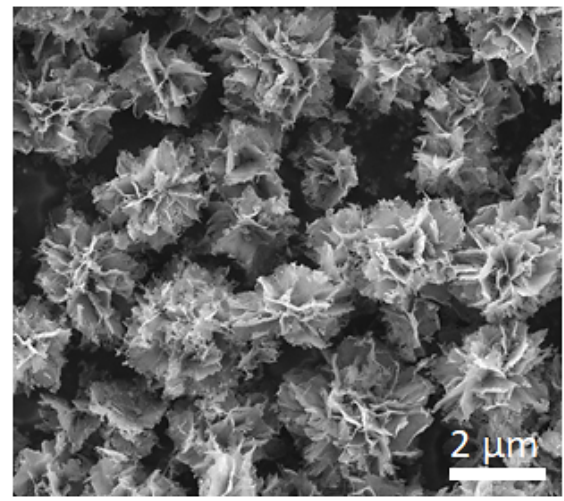

e

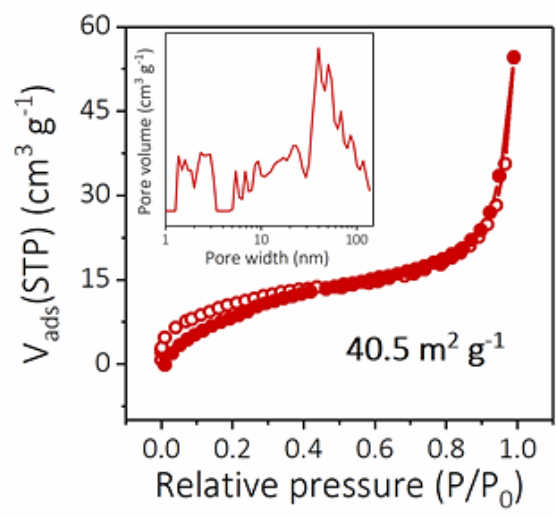

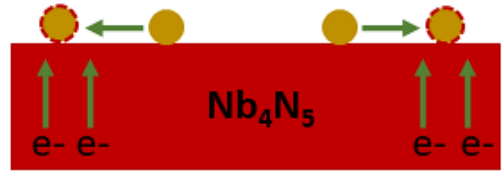

C

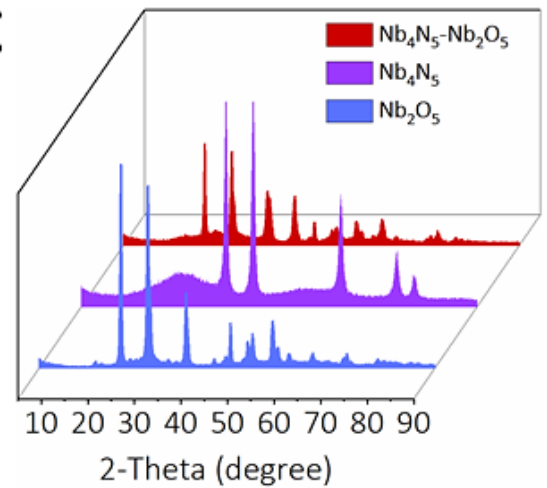

$f$

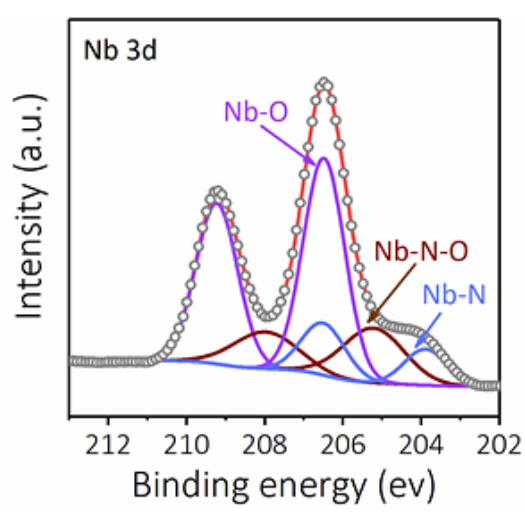

$\mathrm{Nb}_{4} \mathrm{~N}_{5}-\mathrm{Nb}_{2} \mathrm{O}_{5}$ heterostructure

1. Strong binding 2. Increased nucleation

3. Improved charge 4 . Increased interface diffusion
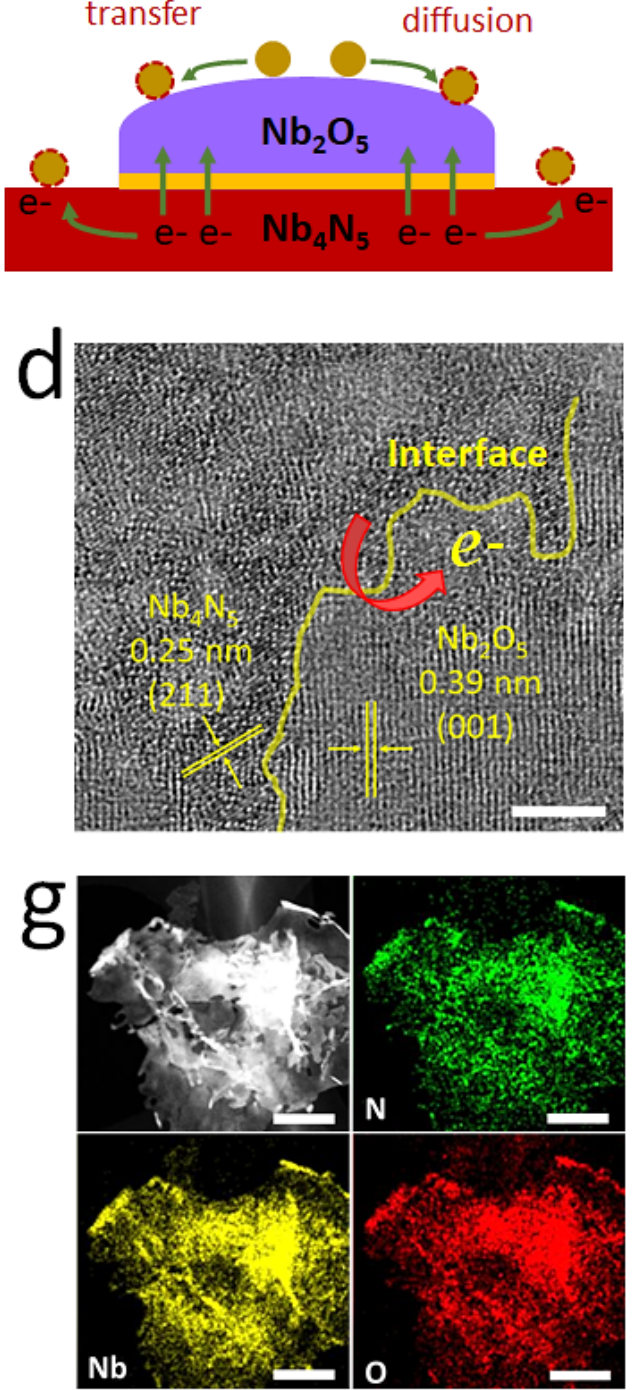

\section{Figure 1}

Schematics of the catalytic mechanism and characterization of Nb4N5-Nb205 Heterostructure. (a) Schematic illustration of the polysulfides anchoring-diffusion-conversion processes on bare 2D Nb205, bare 2D Nb4N5 and 2D Nb4N5-Nb2O5 heterostructure surface. (b) SEM image of Nb4N5-Nb205 heterostructures. (c) XRD patterns of Nb205, Nb4N5 and Nb4N5-Nb205 heterostructure. (d) HRTEM image and (e) nitrogen adsorption-desorption isotherm of Nb4N5-Nb2O5 heterostructure. Inset is its pore size distribution. (f) High-resolution XPS Nb 3d spectrum of Nb4N5-Nb2O5 heterostructure. (g) HAADFSTEM image of Nb4N5-Nb2O5 heterostructure and corresponding element mapping of $\mathrm{N}, \mathrm{Nb}$, and $\mathrm{O}$ element. Scale bars: (b) $2 \mu \mathrm{m}$, (d) $5 \mu \mathrm{m}$, and (g) $300 \mathrm{~nm}$ 
a

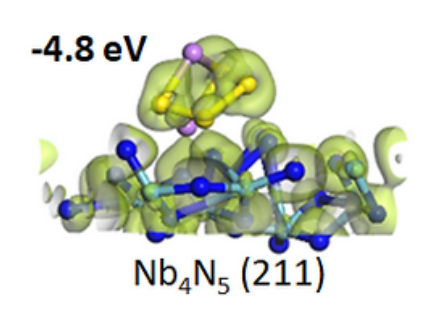

b

- $\mathrm{N} \odot \mathrm{O} \odot \mathrm{Nb} \mathrm{Li}_{2} \mathrm{~S}_{4}$

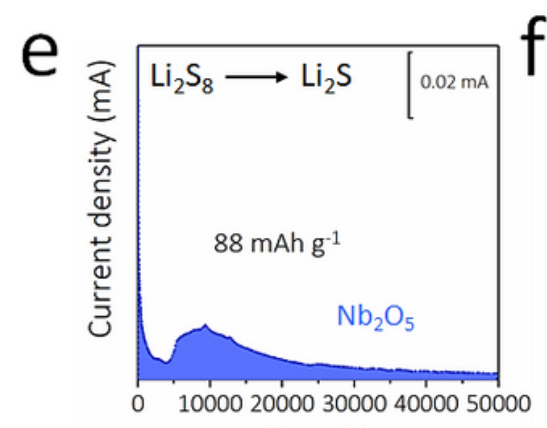

Time (s)

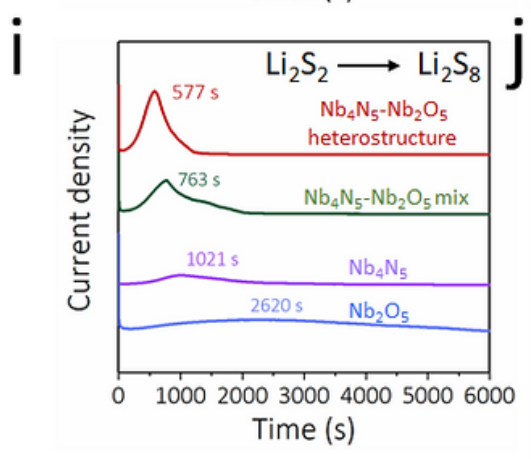

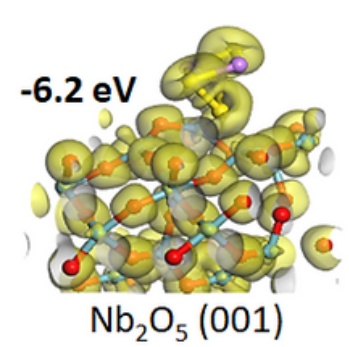

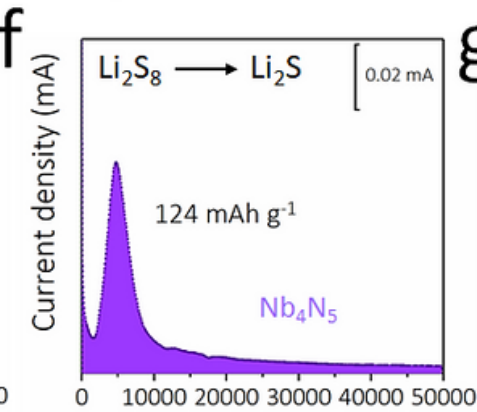

Time $(s)$

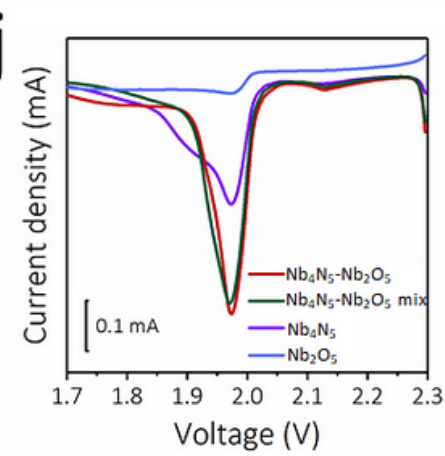

C
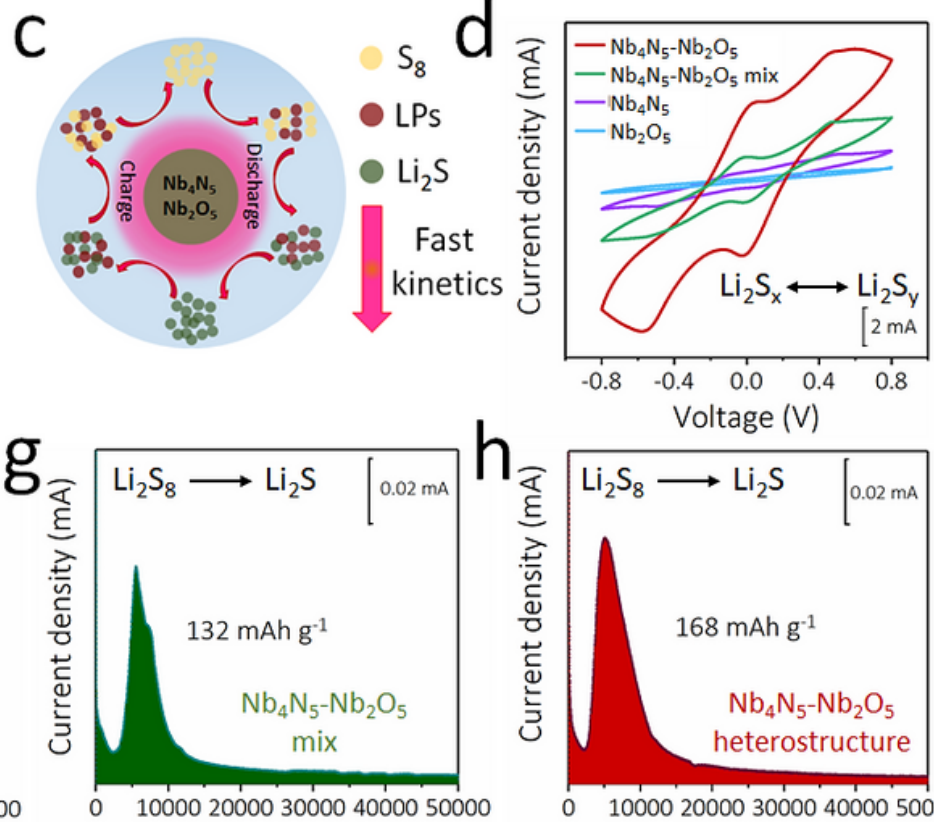

Time (s)

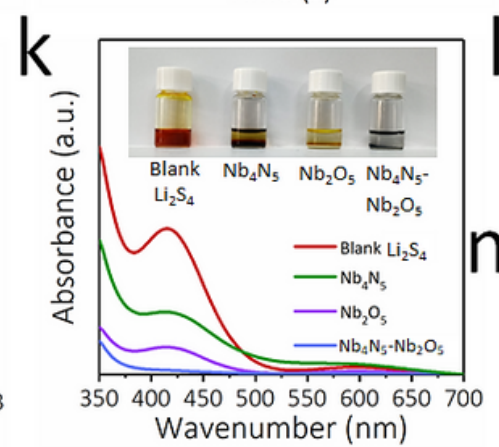

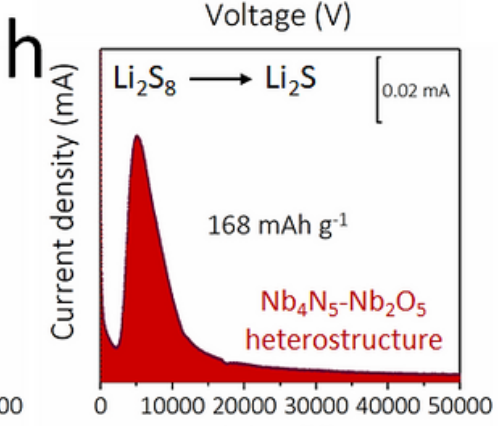

Time (s)
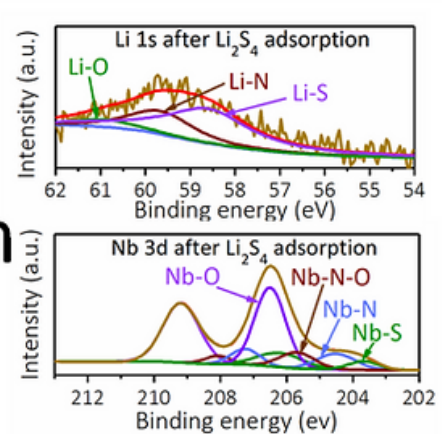

$\mathrm{m}_{\substack{\bar{s} \\ \text { inj }}}$

Figure 2

Electrocatalytic and adsorption effects of Nb4N5-Nb205 heterostructure. (a, b) Optimized geometries and their corresponding binding energies of Li2S4 on (a) Nb4N5 (211) and (b) Nb205 (001) surfaces. (c) Schematic illustration of the reaction pathways of the sulfur cathode catalyzed by Nb4N5-Nb205 heterostructure. (d) CV curves of Li2S6 symmetric batteries employing Nb4N5-Nb2O5 heterostructure, $\mathrm{Nb} 4 \mathrm{~N} 5-\mathrm{Nb} 205 \mathrm{mix}, \mathrm{Nb} 4 \mathrm{N5}$, or Nb205 electrodes obtained at $5 \mathrm{mV}$ s-1. (e-h) Potentiostatic discharge curves of Li2S8 electrolyte discharged at $2.05 \mathrm{~V}$ on the (e) Nb205, (f) Nb4N5, (g) Nb4N5-Nb2O5 mix, and (h) Nb4N5-Nb205 heterostructure, respectively. (i) Potentiostatic charge profiles at $2.40 \mathrm{~V}$ on Nb4N5$\mathrm{Nb} 205$ heterostructure, Nb4N5-Nb205 mix, Nb4N5, and Nb205 electrodes to evaluate the dissolution behaviors of Li2S2. (j) LSV analyses of Nb4N5-Nb205 heterostructure, Nb4N5-Nb205 mix, Nb4N5, and $\mathrm{Nb} 205$ electrodes with Li2S4 catholyte. (k) UV-Vis spectra of Li2S4 with variation in color upon adsorption by blank Li2S4 solution, Nb4N5, Nb205, and Nb4N5-Nb2O5 heterostructure. (l, m) Highresolution XPS (I) Li 1s and (m) Nb 3d spectra of Nb4N5-Nb2O5 heterostructure after adsorption of Li2S4. 

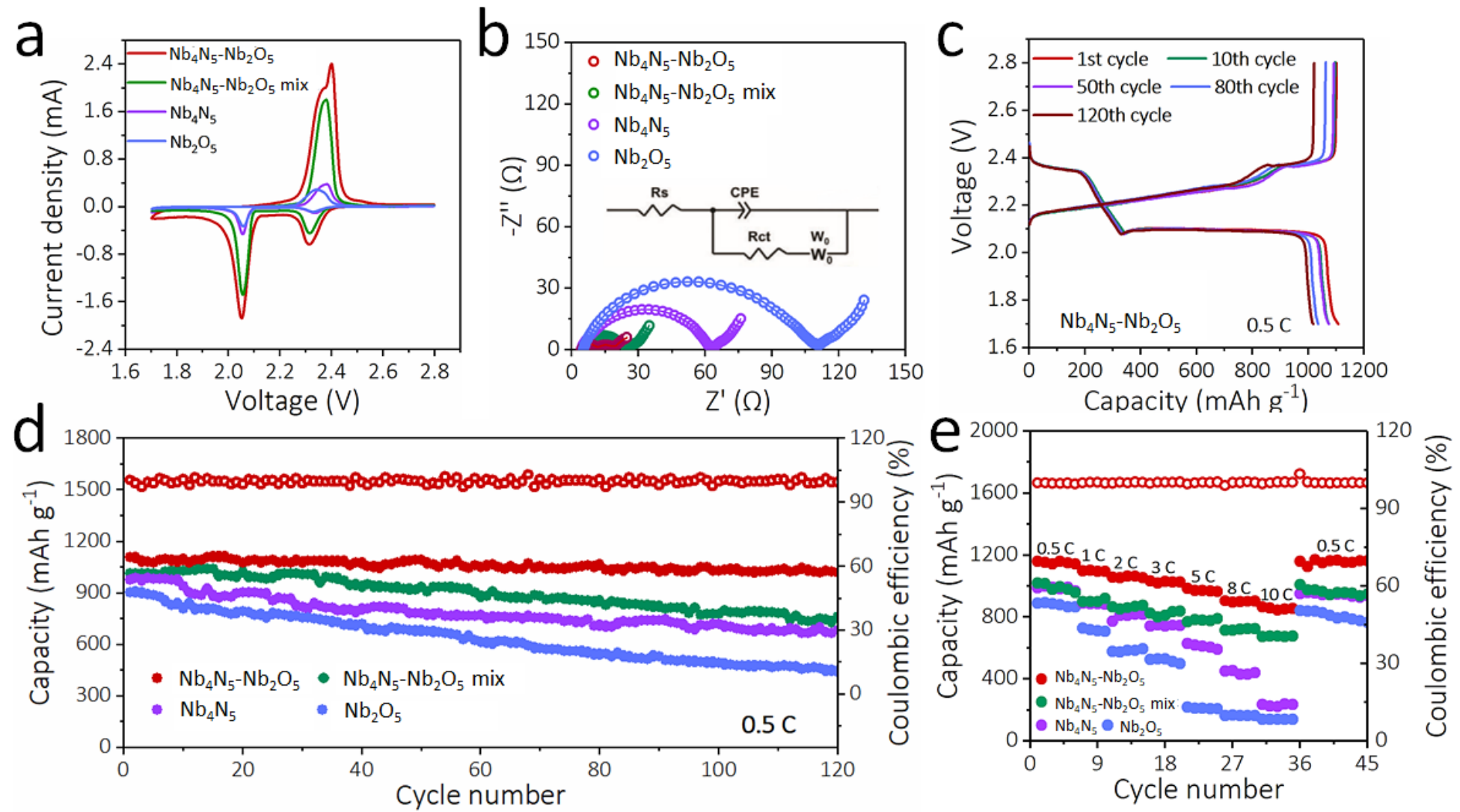

\section{Figure 3}

The electrochemical performance of Li-S battery based on Nb4N5-Nb205 Cathode. (a) CV curves of Li-S batteries using $\mathrm{Nb} 4 \mathrm{N5} 5-\mathrm{Nb} 2 \mathrm{O} 5$ heterostructure, Nb4N5-Nb2O5 mix, Nb4N5, and Nb2O5 electrodes as the sulfur hosts obtained at a scan rate of $1 \mathrm{mV}$ s-1. (b) Nyquist plots of Li-S batteries with different cathodes before cycling. (c) Galvanostatic charge and discharge profiles of Li-S batteries with Nb4N5-Nb2O5 cthode at 0.5 C. (d) Cycling performance of Li-S batteries with Nb4N5-Nb2O5 heterostructure, Nb4N5$\mathrm{Nb} 205$ mix, Nb4N5, and Nb205 electrodes at 0.5 C. (e) Rate performance of Li-S batteries with different cathodes. 

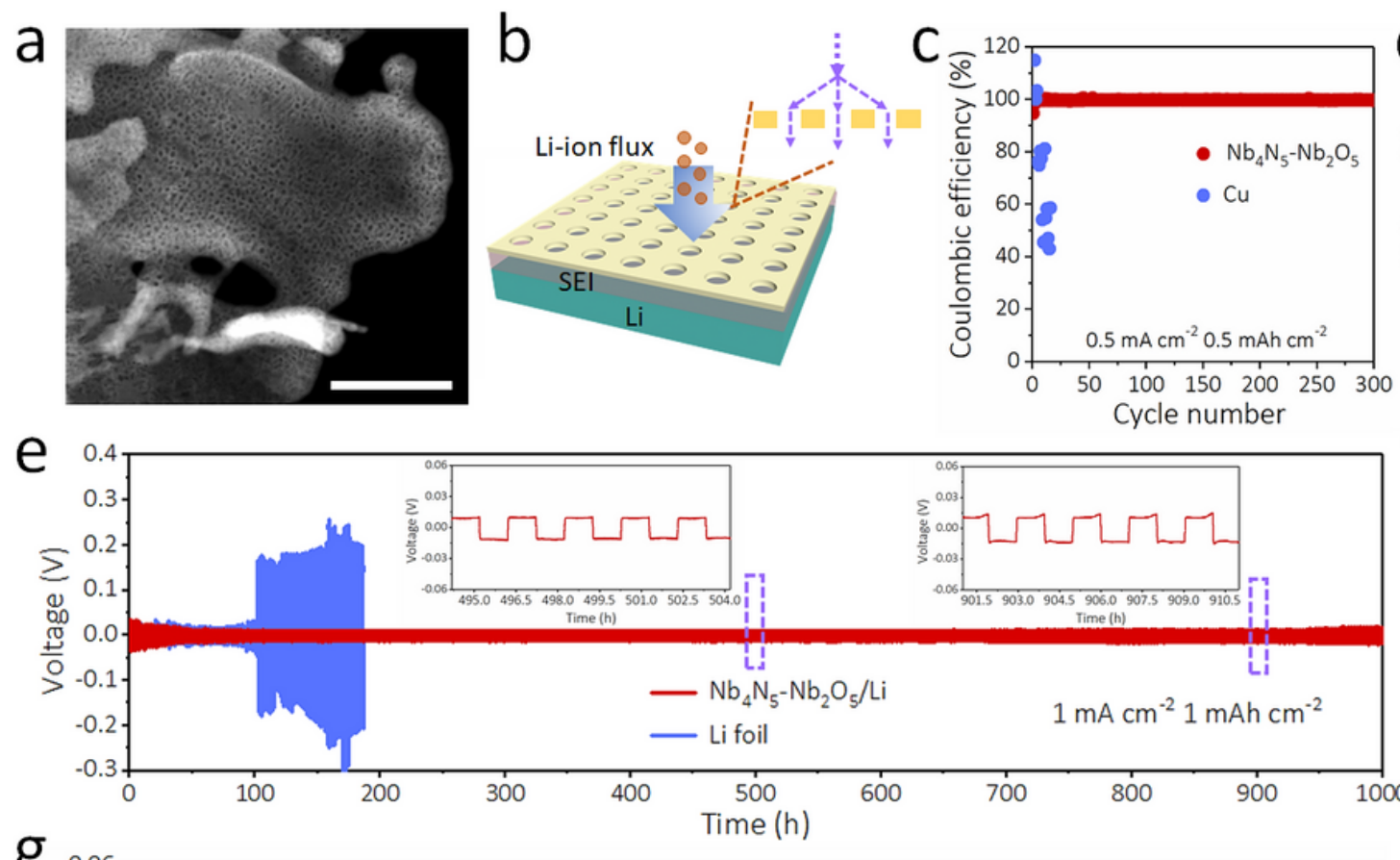

g

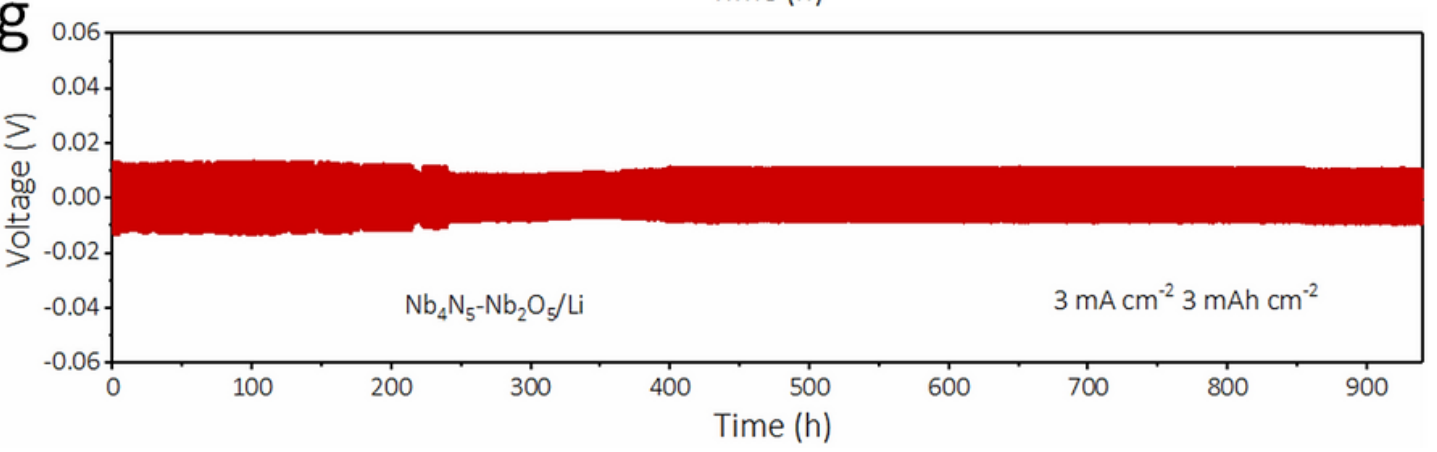

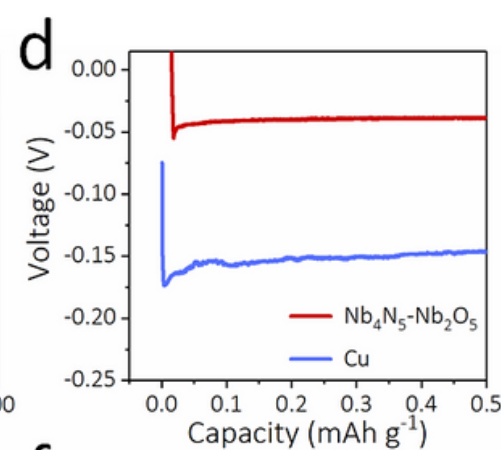

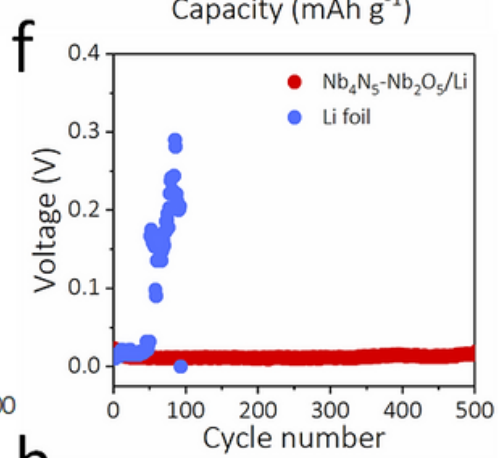

$\mathrm{h}$

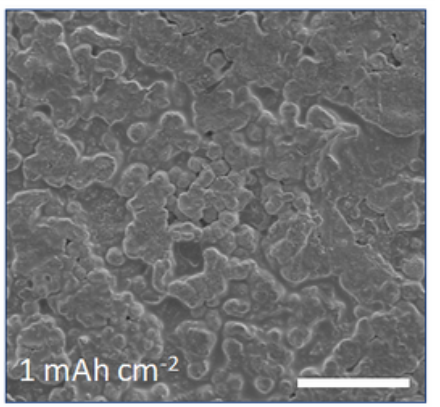

\section{Figure 4}

Lithium dendrite suppression of Nb4N5-Nb2O5 heterostructure. (a) High angle annular dark fieldscanning transmission electron microscope/microscopy (HAADF-STEM) image of Nb4N5-Nb205 heterostructure. (b) Schematic illustration of the Li-ion redistribution behavior of the holey Nb4N5-Nb205 for dendrite-free Li anode. (c) Coulombic efficiencies and (d) enlarged plating-striping curves of Nb4N5$\mathrm{Nb} 205$ and Cu foil electrodes at current density of $0.5 \mathrm{~mA} \mathrm{~cm}-2$ with the capacity of $0.5 \mathrm{mAh} \mathrm{cm-2.} \mathrm{(e)}$ Voltage profiles of the symmetric batteries based on Nb4N5-Nb205/Li and Cu-Li electrodes at current

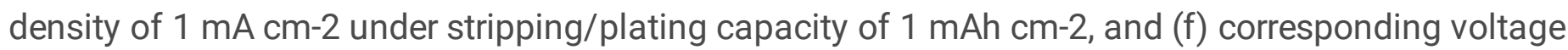
hysteresis variation with cycling number. Inset of $(e)$ is the enlarged voltage-time curves at different times. $(\mathrm{g})$ Voltage profile of the symmetric batteries with different electrodes at current density of $3 \mathrm{~mA}$ $\mathrm{cm}-2$ with a capacity of $3 \mathrm{mAh} \mathrm{cm}-2$. (h) SEM image of Nb4N5-Nb205/Li electrode after cycling. Scale bars: (a) $50 \mathrm{~nm}$, and (h) $50 \mu \mathrm{m}$ 

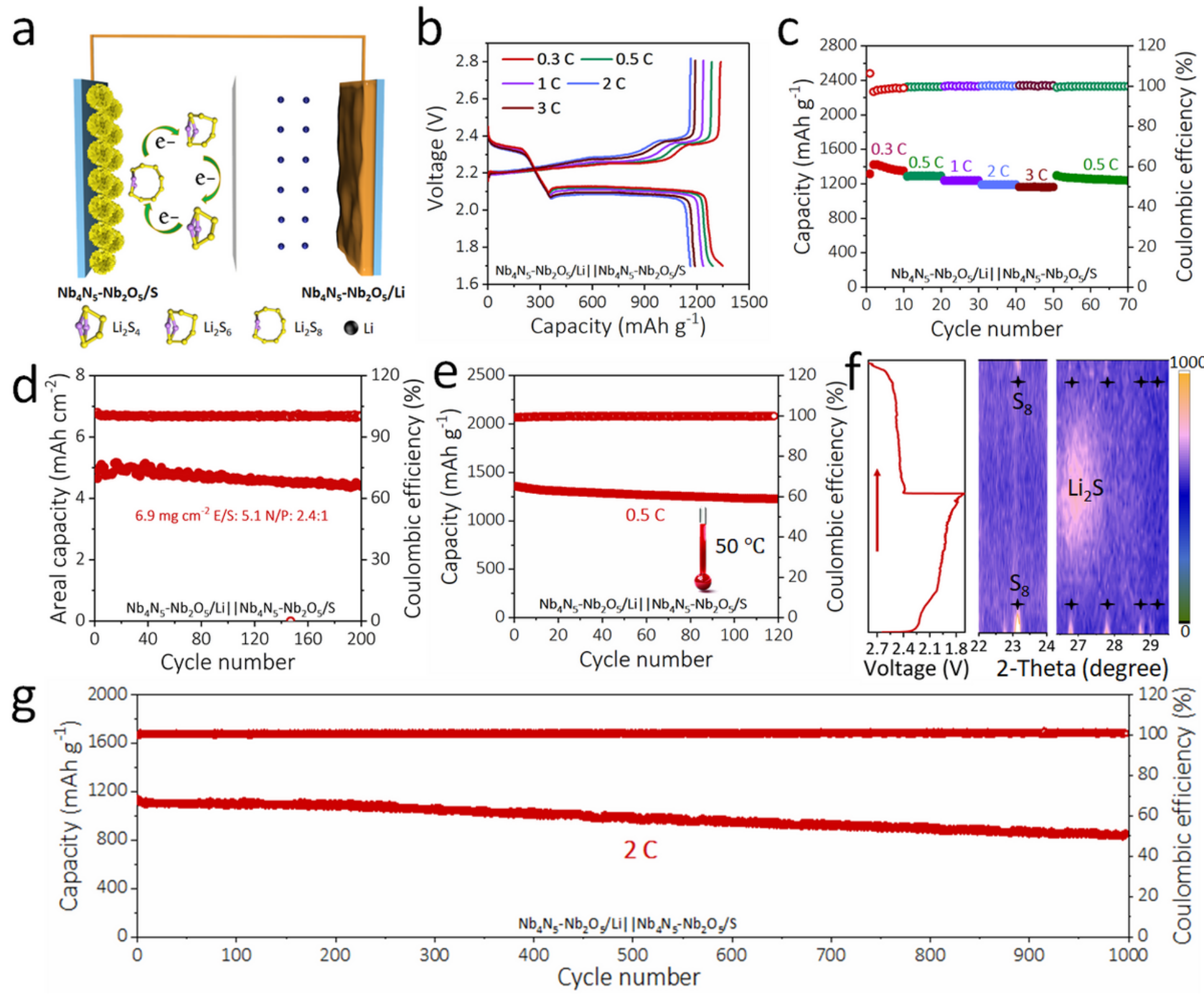

Figure 5

Performance of Nb4N5-Nb205/Li||Nb4N5-Nb205/S full battery. (a) Schematic configuration of Nb4N5$\mathrm{Nb} 205$ heterostructure based Li-S full batteries. (b) Galvanostatic charge and discharge profiles of Nb4N5-Nb205/Li||Nb4N5-Nb205/S batteries obtained at various rates. (c) Rate capability of Nb4N5Nb205/Li||Nb4N5-Nb205/S full batteries. (d) Areal capacity of Nb4N5-Nb205/Li||Nb4N5-Nb205/S battery obtained at $0.3 \mathrm{C}$ with high sulfur loading of $6.9 \mathrm{mg} \mathrm{cm}-2$. (e) Cycling performance of the Nb4N5-

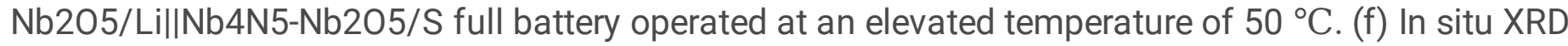
contour plots of the Nb4N5-Nb205/Li||Nb4N5-Nb205/S cathode with the corresponding dischargecharge curves on the left and the diffraction intensity chart on the right. (g) Long-term cycling stability of 1000 cycles of Nb4N5-Nb205/Li||Nb4N5-Nb205/S battery measured at 2 C.

\section{Supplementary Files}


This is a list of supplementary files associated with this preprint. Click to download.

- SupportingInformation.docx 